\title{
Apolipoprotein E Polymorphism and Alzheimer's Risk in Kashmiri Population
}

\author{
Kamran Nissar ${ }^{1,3}$, Arshad Hussain ${ }^{2}$ and Bashir Ahmad Ganai ${ }^{3 *}$ \\ ${ }^{1}$ Department of Biochemistry, Faculty of Biological Sciences, \\ University of Kashmir, Srinagar, Jammu and Kashmir, India. \\ ${ }^{2}$ Department of Psychiatry, Faculty of Neurosciences, Institute of Mental Health and \\ Neurosciences, Srinagar, Jammu and Kashmir, India. \\ ${ }^{3}$ Centre of Research for Development, Faculty of Multidisciplinary Research Centre, \\ University of Kashmir, Srinagar, Jammu and Kashmir, India. \\ http://dx.doi.org/10.13005/bbra/2950
}

(Received: 19 June 2021; accepted: 10 November 2021)

\begin{abstract}
Although the cause of Alzheimer's disease is unknown, most experts feel that the disease is caused by a combination of circumstances rather than a single cause. Age, gene polymorphism, diabetes, and other conditions are all risk factors for Alzheimer's disease. Given the importance of gene polymorphism in different diseases, we intended to find out the association of $A P O E$ gene polymorphism with Alzheimer's risk in the Kashmiri population. Out of 300 patients who were referred to the memory clinic of the hospital, we conducted the study on 59 clinically confirmed Alzheimer's patients and 52 age and ethnicity-matched healthy controls found in a community survey. Our data revealed a statistically significant association of $\varepsilon 4$ variant genotype of the $A P O E$ gene with $\mathrm{AD}$ susceptibility in the Kashmiri population. The current study's findings provided insight into the role of APOE polymorphisms in Alzheimer's disease susceptibility. The identified susceptibility variant may become a marker genotype for AD.
\end{abstract}

Keywords: Alzheimer's disease (AD); Apolipoprotein E (APOE); $\varepsilon 2$, $\varepsilon 3$ and $\varepsilon 4$ isoforms; Polymorphism; $\beta$-Amyloids.

Alzheimer's disease is a condition that affects people as they get older. It is the most frequent type of dementia, affecting people between the ages of 60 and 65 . Amyloid beta (A) plaques are thought to be the main cause of the disease's progression in this neurodegenerative condition. Amyloid plaques are hypothesised to build up in the brain, causing inflammation and, as a result, triggering an immunological response that leads to neurodegeneration. The prevalence of neurodegenerative diseases has been reported to rise with age. Alzheimer's disease is a composite disease with both inherited and environmental variables influencing its genesis. The sporadic form of $\mathrm{AD}$ accounts for more than $90 \%$ of all cases ${ }^{1}$. The genetic heritability of Alzheimer's disease (including memory components) ranges from 49 percent to 79 percent, according to twin and family studies $^{2,3}$. Familial (genetic) varieties of autosomal (not sex-linked) dominant inheritance with onset 
before the age of 65 account for about 0.1 percent of Alzheimer's disease cases. Familial (genetic) varieties of autosomal (not sex-linked) dominant inheritance with onset before the age of 65 account for about 0.1 percent of Alzheimer's disease cases $^{4,25}$. Early-onset familial Alzheimer's disease is the name given to this type of Alzheimer's disease (AD), this type of Alzheimer's disease (AD) that is significantly connected to mutations in the presenilin 1 and 2 proteins and the amyloid precursor protein (APP) $)^{5}$.

Despite extensive efforts, our understanding of $\mathrm{AD}$ heredity remains limited. For Late Onset Alzheimer's Disease, apolipoprotein E gene (APOE) has been identified as a major disease susceptibility gene ${ }^{6,7}$. APOE is a basic lipid transport protein produced mostly by astrocytes ${ }^{8}$. Multiple factors have been linked to late-onset sporadic $\mathrm{AD}$, including advancing age, genetic factors such as the APOE variant, brain injury, dietary factors, immune system, and others. All of these factors may play a role in Alzheimer's disease by increasing the production of free radicals with age and putting stress on regulatory genes in early and later life (the "dual hit hypothesis") APOE $\varepsilon 2$, APOE $\varepsilon 3$, and APOE $\varepsilon 4$ are the three allele of apolipoprotein E. The APOE $\varepsilon 4$ allele is a substantial risk factor having the odds ratio (OR) ranging from 2.0 to 4.0 in comparison to the APOE $\varepsilon 3$ allele, with the APOE $\varepsilon 2$ allele being protective against Late Onset Alzheimer's Disease ${ }^{9,10}$. The APOE $\varepsilon 4$ is a key genetic risk factor for Alzheimer's disease. While apolipoproteins contribute in the breakdown of amyloid plaques, some isoforms (such as APOE ع4) are ineffective, resulting in an excess of amyloid precursor in the brain ${ }^{11}$. According to studies, transgenic mice expressing a mutant form of the human APP gene developed fibrillar amyloid plaques and Alzheimer's disease (AD)-like brain pathology, as well as spatial learning deficits ${ }^{12}$.

\section{MATERIAL AND METHODS}

The study included 59 clinically confirmed AD patients out of 300 patients who were referred to the memory clinic of the Institute of Mental Health and Neurosciences, Kashmir. All the enrolled patients for the study were diagnosed with Alzheimer's disease. The baseline diagnostic work- up included mini-mental state examination (MMSE) (Table 1), magnetic resonance imaging (MRI) and computed tomography (CT), depending on the requirement. The MMSE (Kashmiri version) is a validated and standardized tool for our population. Patients scoring below 24 on MMSE (Kashmiri version $)^{13}$ were further evaluated, and diagnosis of Alzheimer's dementia was made as per DSM IV-TR criteria for dementia of Alzheimer's type. Simultaneously 52 controls with age and gendermatched, unrelated individuals of similar ethnicity, who were free of any chronic or psychiatric disease, were recruited randomly from among individuals in a community survey. Controls were screened for dementia by MMSE (Kashmiri version) ${ }^{13}$ and individuals scoring above a minimum cut-off of 24 were included. To avoid any ethnicity variation in both groups (Cases and Controls) all study subjects were of Kashmir descent and had been residents of Kashmir. In the interview, data on demographical details, family history of Alzheimer's disease, etc. were taken from controls, patients and their close attendants. Controls, as well as patients or their close attendants (if the need arose), were informed and proper consent was taken, thereafter about $5 \mathrm{ml}$ of the peripheral blood sample was obtained from every individual. Approval to conduct the study was obtained through the Ethical Committee of the Institute.

The genomic DNA was isolated from lymphocytes in the peripheral blood using the salting out method with some modifications ${ }^{14}$. Genomic DNA was amplified in a total volume of $25 \mu \mathrm{l}$, containing $17.5 \mu \mathrm{l}$ of nuclease-free water, $1.5 \mu \mathrm{l}$ of dNTPs, $1 \mu 1$ of both forward and reverse primers having a concentration of 10 pmoles, $2 \mu \mathrm{l}$ of $1.5 \mathrm{mM} \mathrm{Mgcl} 2,2 \mu \mathrm{l}$ of buffer and 2U Taq polymerase. The primer sequences $\mathrm{F} 52$ ACAGAATTCGCCCCGGCCTGGTACAC 32 ; R 52 TAAGCTTGGCACGGCTGTCCAAGGA $32^{15}$ were used in the amplification of DNA fragment of interest. The amplification process included initial denaturation for 5 minutes at $95^{\circ} \mathrm{C}$ which was succeeded by denaturation for $30 \mathrm{sec}$. at $95^{\circ} \mathrm{C}$, annealing for $30 \mathrm{sec}$. at $60^{\circ} \mathrm{C}$, and an extension for $59 \mathrm{sec}$. at $72^{\circ} \mathrm{C}$, all repeated (except initial denaturation) 30 times i.e, 30 cycles, lastly the final extension was for 9 minutes at $72^{\circ} \mathrm{C}$. The polymorphic analysis was based on Polymerase Chain Reaction (PCR) followed by sequencing. 
The $\chi 2$ test was used to determine the statistical significance of differences in genotype frequencies between patients and controls. For all analysis variables, binary logistic regression was used to estimate risk as an odds ratio (OR) with a 95 percent confidence interval (CI) using age and sex as covariates. All statistical analyses were carried out with SPSS software version 16.0 (SPSS, Chicago, Illinois, USA), with two-sided tests of statistical significance and differences considered significant when the p-value was less than 0.05 . All ORs were adjusted for age and gender.

\section{RESULTS}

Age and ethnicity were taken into account when comparing cases and controls. Among recruited patients $39(66.1 \%)$ were having MMSE

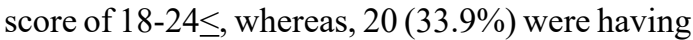
MMSE score of $\leq 18$. In case of controls all 52

Table 1. Mini Mental Score Examination

\begin{tabular}{|c|c|c|}
\hline Contant & $\begin{array}{c}\text { Controls } \\
\mathrm{n}(\%)\end{array}$ & $\begin{array}{l}\text { Cases } \\
\mathrm{n}(\%)\end{array}$ \\
\hline $\mathrm{MMSE} \geq 24$ & $52(100)$ & $0(0)$ \\
\hline Between 18-24= & $0(0)$ & $39(66.1)$ \\
\hline$\leq 18$ & $0(0)$ & $20(33.9)$ \\
\hline
\end{tabular}

$\mathrm{n}$-Number of individuals
$(100 \%)$ were having MMSE score of $\geq 24$. To test if the variant genotypes were connected with AD vulnerability, we examined the genotype distribution of controls and AD patients. To identify polymorphic variations, PCR amplification was followed by electrophoresis in a 1.5 percent Agarose gel containing ethidium bromide. The lane $1,2,3,4 \& 5$ was loaded with amplified products and lane $\mathrm{M}$ were loaded with $100 \mathrm{bp}$ DNA (fig. 1). The polymorphic analysis was based on Polymerase Chain Reaction (PCR) followed by sequencing (fig.2-fig.7). We attempted to examine the isoform distribution in cases and controls, and discovered that the $\varepsilon 4$ variant is present in a considerably higher percentage (58.4\% vs $17.31 \%)$ in cases than in controls (OR 5.6, 95\% $\mathrm{CI}=2.8-4.2, \mathrm{p}<0.00001)$ ), thus strongly associated with AD development. Huge difference was found in $\varepsilon 2$ allele frequency (16.10\% vs $40.38 \%)$ in cases and controls (OR $0.6,95 \% \mathrm{CI}=0.3-1.3, \mathrm{P}=0.25)$ suggestive of its protective role. One may say that there is the decreased efficiency of metabolism in the $A P O E$ $\varepsilon 4$ variant that leads to the build up of amyloid beta $(\mathrm{A} \beta)$ plaques and thereby $\mathrm{AD}$. The association of $A P O E$ gene polymorphism with $\mathrm{AD}$ has been presented in Table 2.

\section{DISCUSSION}

Alzheimer's disease, commonly known as Alzheimer's dementia, is a scary and

Table 2. Association of $A P O E$ with Alzheimer's disease

\begin{tabular}{lcccc}
\hline $\begin{array}{l}\text { And } A P O E \\
\text { (Isoform) } \\
\text { Variants }\end{array}$ & Controls & Cases & OR $(95 \% \mathrm{CI})$ & p value \\
\hline$\varepsilon 3 \varepsilon 3$ & & & \\
$\varepsilon 2 \varepsilon 2$ & $9(17.30 \%)$ & $10(16.95 \%)$ & Reference & \\
$\varepsilon 2 \mathrm{v} 3$ & $17(32.70 \%)$ & $0(0 \%)$ & & \\
$\varepsilon 2 \mathrm{v} 4$ & $8(15.39 \%)$ & $0(0 \%)$ & & \\
$\varepsilon 4 \mathrm{v} 3$ & $0(0 \%)$ & $19(32.20 \%)$ & & \\
$\varepsilon 4 \varepsilon 4$ & $18(34.61 \%)$ & $10(16.95 \%)$ & $0.5(.15-1.63)$ & \\
$\varepsilon 2 \varepsilon 3+\varepsilon 2 \varepsilon 2$ & $25(48.07 \%)$ & $20(33.90 \%)$ & & \\
$\varepsilon 4 \varepsilon 3+\varepsilon 4 \varepsilon 4$ & $18(34.61)$ & $30(50.85 \%)$ & $1.5(0.5-4.3)$ & 0.45 \\
Allele $\varepsilon 3$ & $44(42.31 \%)$ & $30(25.5 \%)$ & Reference & \\
Allele $\varepsilon 2$ & $42(40.38 \%)$ & $19(16.10)$ & $0.6(0.3-1.3)$ & 0.25 \\
Allele $\varepsilon 4$ & $18(17.31)$ & $69(58.4 \%)$ & $5.6(2.8-4.2)$ & 0.00001 \\
\hline
\end{tabular}

Significant values shown in bold. OR — Odds Ratio, CI — Confidence Interval, $\mathrm{n}$ - Number of individuals. 
debilitating neurological ailment characterised by neurodegeneration that alters a person's typical personality. Alzheimer's disease often strikes people between the ages of 60 and 65. It is the most common form of dementia. Alzheimer's disease is a complex disease with a hereditary and environmental aetiology. The sporadic form of Alzheimer's disease accounts for more than $90 \%$ of all cases ${ }^{1}$. In this work, we attempted to link APOE gene polymorphism to Alzheimer's disease risk in a small case-control study among the Kashmiri ethnic group.

Apolipoprotein $\mathrm{E}$ has three alleles, $A P O E-\varepsilon 2, A P O E-\varepsilon 3$ and $A P O E-\varepsilon 4$. Two single nucleotide polymorphisms (SNPs) that aren't synonymous have defined these three alleles, rs 429358 (TGC'! CGC) and rs 7412 (CGC '!TGC): $A P O E-\varepsilon 2$ (T-T); $A P O E-\varepsilon 3$ (T-C); and $A P O E-\varepsilon 4$ (C-C). Out of these three alleles, the $A P O E-\varepsilon 3$ is the most frequent $(0.49-0.91), A P O E-\varepsilon 2$ is the rarest $(0.0-0.15)$, in all populations thus far investigated ${ }^{16}$ (Corbo et al. 1999). The frequencies of the $A P O E-\varepsilon 2, A P O E-\varepsilon 3$ and $A P O E-\varepsilon 4$ alleles in Japanese normal controls ( $\geq 60$ years) are 0.05 , 0.86 and 0.09 respectively ${ }^{17},{ }^{18}$. The $A P O E-\varepsilon 4$ allele poses a strong risk as compared to $A P O E-\varepsilon 3$ allele, with an odds ratio (OR) of 2.0-4.0, whereas, $A P O E-\varepsilon 2$ appears to be protective against LOAD (late onset Azlheimer's disease) ${ }^{9,10}$. APOE $\varepsilon 4$ have been found to be associated with the cognition decline among adults in tasks involving memory and learning ${ }^{20,21}$. The interplay of inflammation, APOE, and $A \beta$ plaques can produce cognitive decline and cerebrovascular dysfunction ${ }^{22}$. Increased Aâ deposition has also been reported by number of studies among those who carry $A P O E \varepsilon 4$ allele ${ }^{23,21}$. According to Fryler (2003), the APOE 4 allele accelerated age-dependent cerebral amyloid angiopathy in transgenic mice ${ }^{24}$. Expression level of $A P O E$ and $\mathrm{A} \beta$ deposition were found to have inverse relation ${ }^{26}$. Increased $A \beta$ deposition appeared to be strongly associated to $A P O E$ $\varepsilon 4$ allele $^{26}$. A meta-analysis of data of Chinese population from January 2000 to November 2013, indicated statistically significant association between $\varepsilon 4$ and $\mathrm{AD}$ in Chinese population (OR $3.93,95 \% \mathrm{CI}=3.37-4.58, \mathrm{p}<0.00001)$. The frequency of the $\varepsilon 3$ isoform was similarly shown to be lower in Alzheimer's disease patients than in healthy controls ${ }^{19}$. Furthermore $\varepsilon 4 / \varepsilon 4$ and $\varepsilon 4 /$

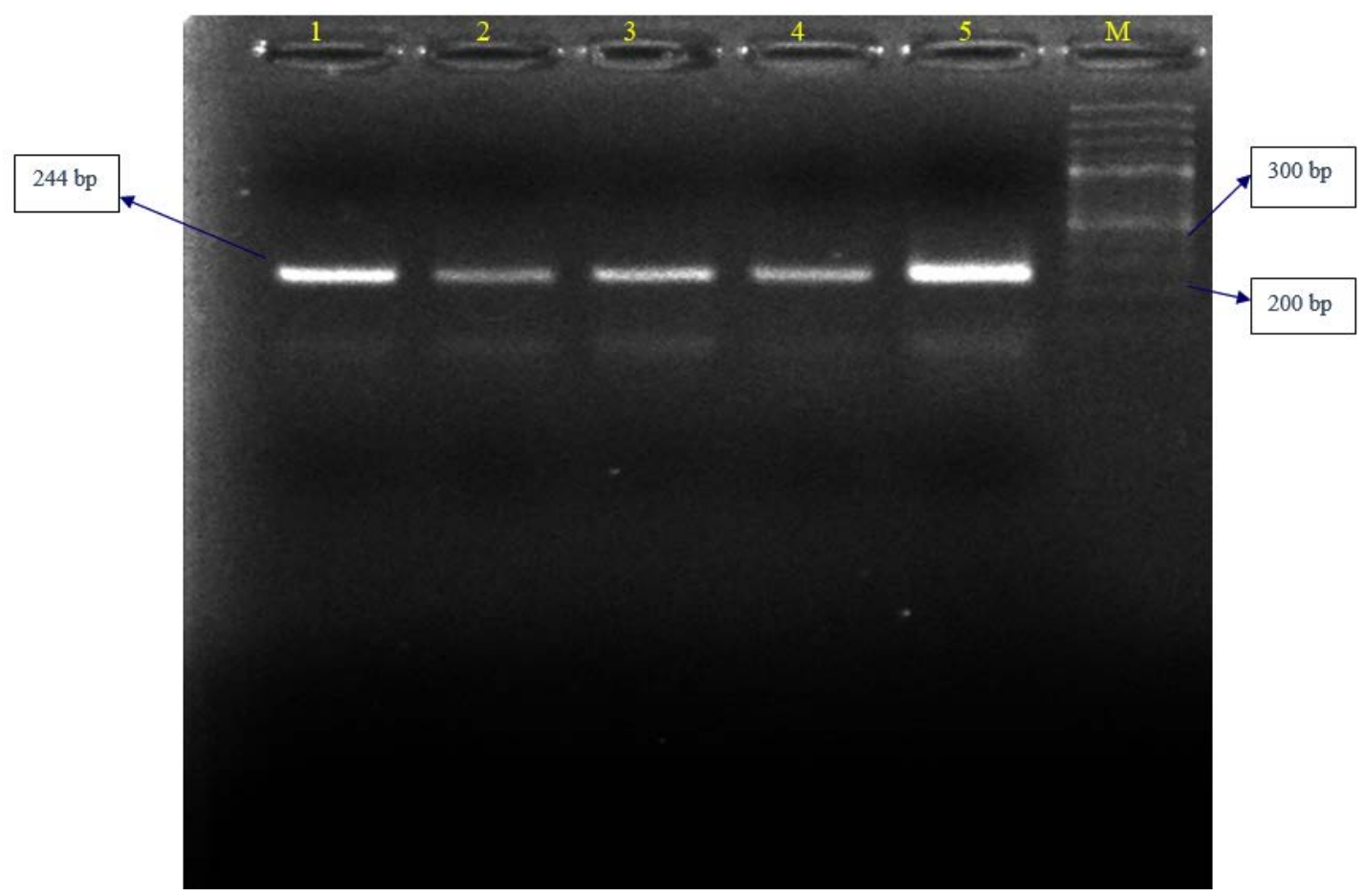

Fig. 1. Representative gel picture of amplicon of APOE gene. Lane 1,2,3,4 and 5: 244 bp PCR product, Lane M: 100 bp ladder 
$\varepsilon 3$ also showed significant association with $\mathrm{AD}^{19}$. Our findings are consistent with the meta-analysis findings for the Chinese population. In Kashmiri population $\varepsilon 4$ allele is also found to be strongly associated (OR 5.6, 95\% $\mathrm{CI}=2.8-4.2$ ) with $\mathrm{AD}$ development. The frequency of the $\varepsilon 3$ allele was found to be lower in Alzheimer's disease patients than in controls. With regard to $\varepsilon 2$ allele frequency there is a huge difference $(16.10 \%$ vs $40.38 \%)$ in cases and controls (OR $0.6,95 \% \mathrm{CI}=0.3-1.3$, $\mathrm{P}=0.25$ ) suggestive of its protective role, whereas, $\varepsilon 4$ allele is concerned the frequency was found to be $58.4 \%$ among $\mathrm{AD}$ cases and only $17.31 \%$ among healthy controls (OR 5.6, 95\% CI=2.8-4.2, $\mathrm{p}<0.00001)$ indicating it strong association with disease (Alzheimer disease) progression.

\section{CONCLUSION}

The findings of this study provided insight on the significance of APOE gene variations in the vulnerability to Alzheimer's disease.

The current investigation found that $A P O E-\varepsilon 4$ isoform of the APOE gene is a strong susceptibility gene variant for AD. One may say that due to the decreased efficiency of metabolism in the $A P O E$ a 4 variant, leads to the build up of amyloid beta (Aâ) plaques and thereby AD.

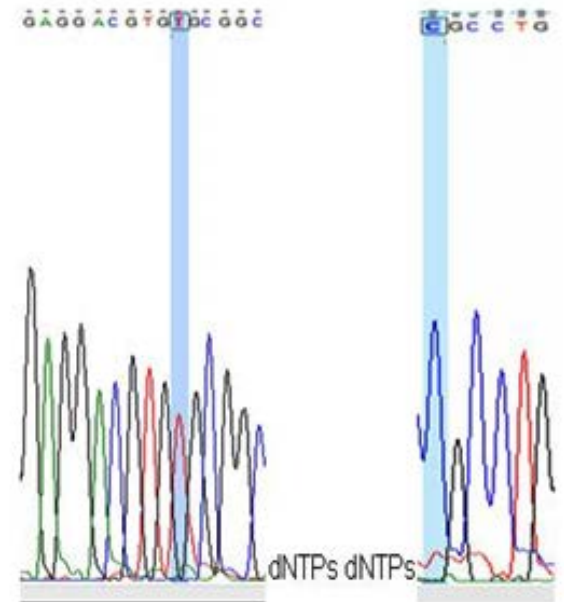

Fig, 2

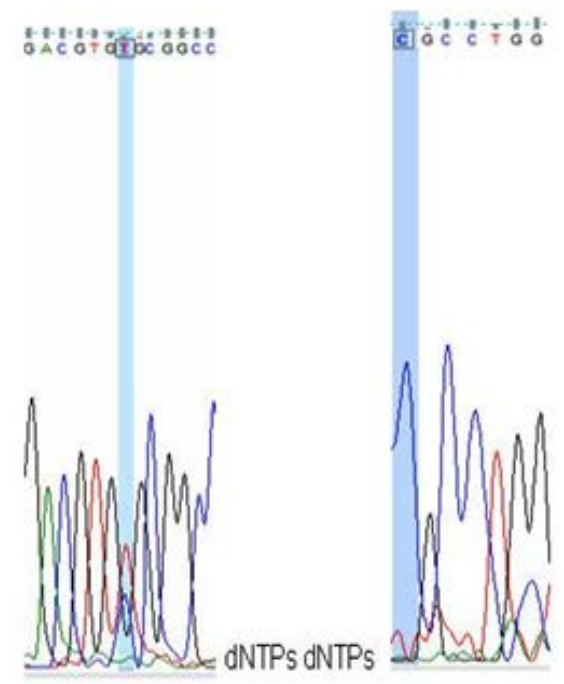

Fig. 4

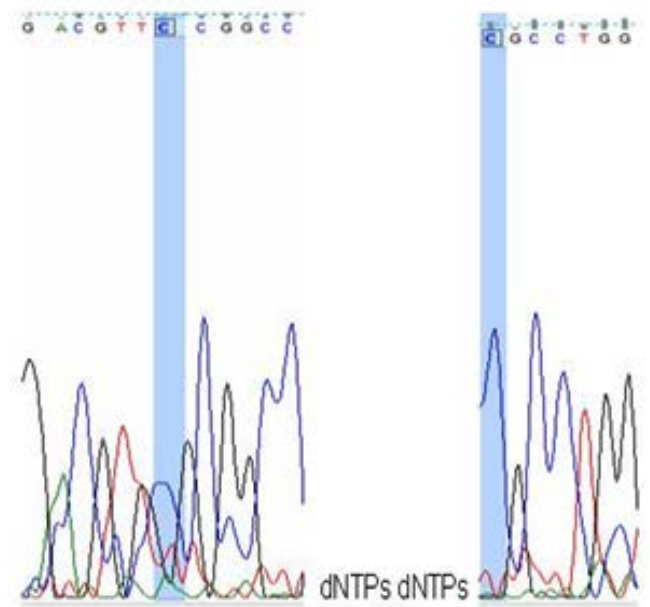

Fig 3

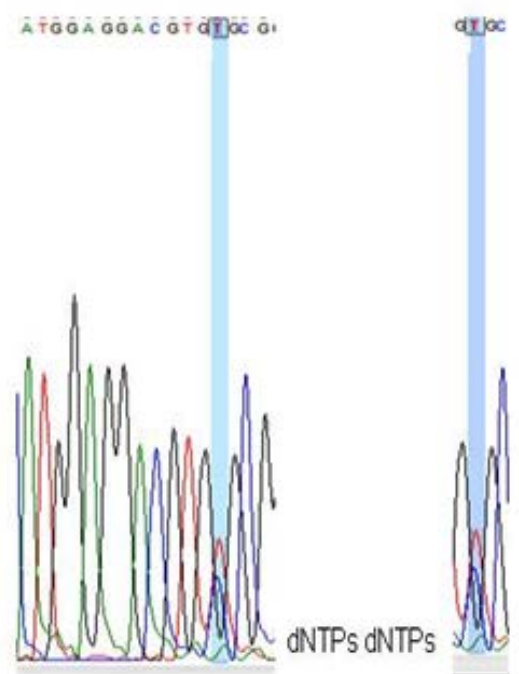

Fig. 5 


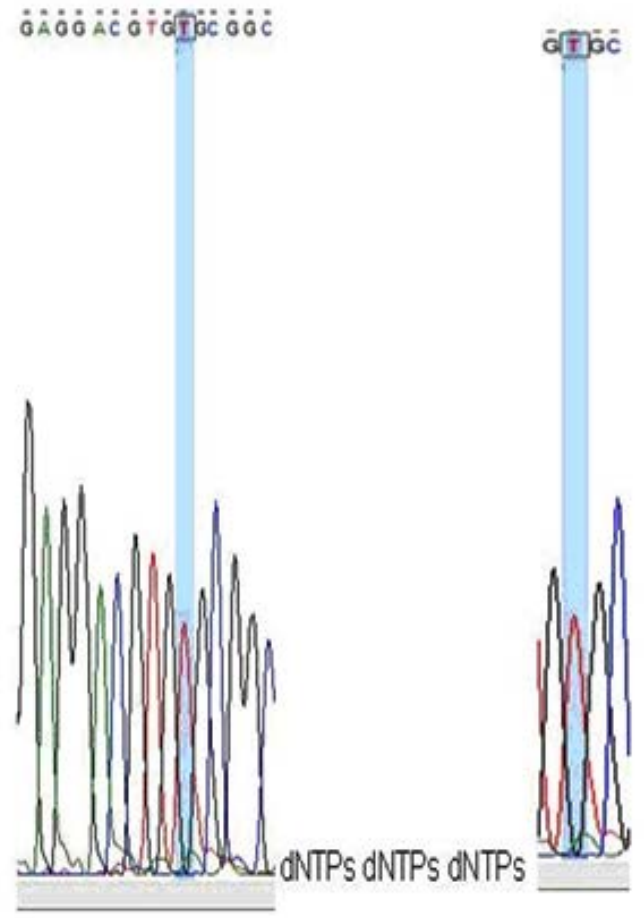

Fig 6
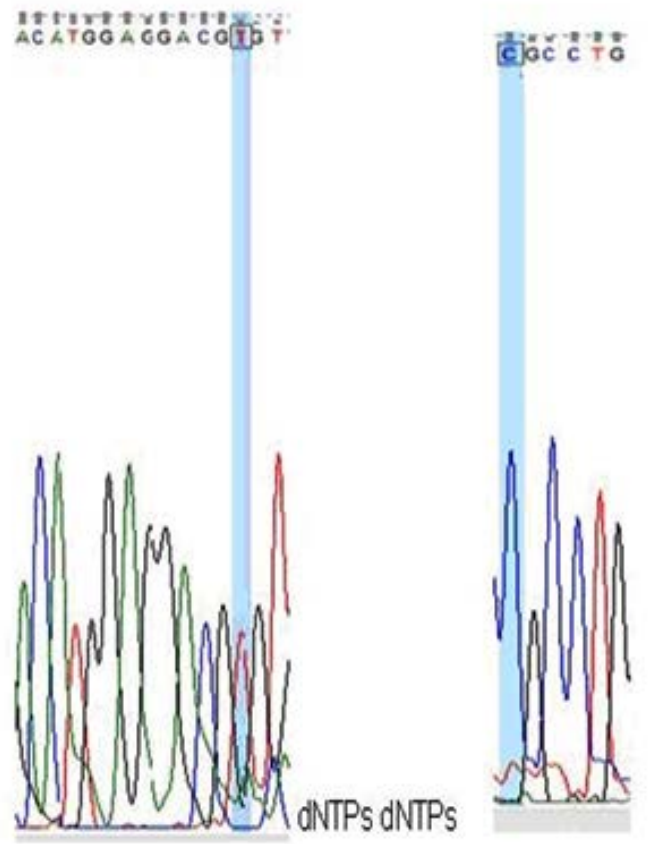

Fig 7

Fig. 2. A to F: Representative Chromatograms of $\varepsilon 3: \varepsilon 3$ genotype (Use as wild/marker), $\varepsilon 4: \varepsilon 4$ genotype, $\varepsilon 3: \varepsilon 4$ genotype, $\varepsilon 2: \varepsilon 4$ genotype, $\varepsilon 2: \varepsilon 2$ genotype, $\varepsilon 2: \varepsilon 3$ genotype respectively. Marked regions represent specific nucleotide sequence and dNTPs represent different nucleotides in between the two specific regions

Familial history, dietary habits, physical activity, socioeconomic status play a significant role in AD. Although hereditary traits are unavoidable, dietary habits, can be easily modified, where an individual have to shift from high fatty diet to low fatty diet. Taking our results and role of $A P O E$ gene into consideration avoiding high-carbohydrate, high-fat and high cholesterol (HFHC) diet, in combination with physical activity may prove highly beneficial and help reduce Alzheimer risk. Socioeconomic stress which includes stress due to separation of loved ones and economic backwardness, can be managed by means of counseling, positive behavior and physical activity-like exercise, walking, cycling, playing games etc.

Since this is a pilot project with a low sample size due to a short study time period, therefore candidate gene approaches based on biological pathways relevant in AD etiology, large sample sizes and genotyping are all the relevant strategies required along with the underlying mechanism(s) responsible for these associations.

\section{ACKNOWLEDGMENTS}

This work has been done at the Centre of Research for Development (CORD) University of Kashmir, Srinagar. We would also like to thank the Dept. of Biochemistry University of Kashmir and Institute of Mental Health \& Neurosciences, Srinagar for providing necessary help. We are immensely thankful to the individuals enrolled as Controls and Patients for providing the blood samples to work on.

\section{Funding} Not applicable.

\section{Conflicts of interest}

The authors declare no conflict of interest.

Research involving Human Participants and/ or Animals 


\section{Ethics approval}

The use of blood samples was approved by the Ethical Committee of Government Medical College Srinagar vide Ref. No. 135/ETH/GMC/ ICM.

\section{Informed consent}

Written consent was obtained from all participants/Relative attending patients (depending on the severity of disease).

\section{Disclosure}

Prof. B.A.Ganai and K.Nissar were responsible for the design of the study; K.Nissar conducted research; Drs A.Hussain acquired data; K.Nissar performed statistical analysis; K.Nissar wrote the paper; B.A.Ganai and A.Hussain revised the manuscript details for important intellectual content; K.Nissar, A.Hussain and B.A.Ganai has primary responsibility for the final content. The main purpose to conduct this research is to through some light on Alzheimer's disease. The research was not funded by any funding agency. There is no conflict of interest regarding this piece of work.

\section{REFERENCES}

1. Yu CE, Marchani E, Nikisch G, et al., The N141I mutation in PSEN2: implications for the quintessential case of Alzheimer disease. Arch Neurol. 2010;67:631-633.

2. Gatz M, Reynolds CA, Fratiglioni L, et al., Role of genes and environments for explaining Alzheimer disease. Arch. Gen. Psychiatry,2006; 63(2):168-174.

3. Wilson RS, Barral S, Lee JH, et al., Heritability of different forms of memory in the Late Onset Alzheimer's Disease Family Study. Journal of Alzheimer's Disease,2011;23(2):24955.

4. Blennow K, deLeon MJ,Zetterberg H.Alzheimer's Disease. Lancet,2006;368(9533):387-403.

5. RichardA.Armstrong. Risk factors for Alzheimer's disease. Folia Neuropathol,2019;57(2): 87-105

6. Strittmatter WJ, et al.,. Apolipoprotein E: highavidity binding to beta-amyloid and increased frequency of type 4 allele in late-onset familial Alzheimer disease, Proc. Natl. Acad. Sci. U.S A. 1993; 90:1977-81.

7. Corder EH, et al., Gene dose of apolipoprotein E type 4 allele and the risk of Alzheimer's disease in late onset families. Science, 1999; 261:921-23.

8. Georgette L, Suidan and Gayathri Ramaswamy. Targeting Apolipoprotein E for Alzheimer's Disease: An Industry Perspective. Int. J. Mol. Sci. 2019;20:2161; doi:10.3390/ijms20092161
9. Farrer LA, et al., Effects of age, sex, and ethnicity on the associa tion between apolipoprotein $\mathrm{E}$ genotype and Alzheimer disease. A metaanalysis. APOE and Alzheimer Disease Meta Analysis Consortium, JAMA, 1997;278:1349-1356.

10. Bertram L, McQueen MB, Mullin K, Blacker D, Tanzi RE. Systematic meta-analyses of Alzheimer disease genetic association studies: the AlzGene database. Nat. Genet,2007; 39:1723.

11. Polvikoski T, Sulkava R, Haltia M, et al., Apolipoprotein E, dementia, and cortical deposition of Beta-amyloid protein. The New England Journal of Medicine, 1995; 333(19): 1242-1247.

12. Games D, Adams D, Alessandrini R, et al., Alzheimer-type neuropathology in transgenic mice overexpressing V717F Beta-amyloid precursor protein. Nature, 1995; 373(6514):523527.

13. Raina S, Razdan S, Pandita KK, et al., Ann Indian Acad Neurol,2008;11(2):106-108.

14. Miller S A, Dykes D D and Polesky H F. A simple salting out procedure for extracting DNA from human nucleated cells. Nucleic Acids Research. 1988;3: 1215.

15. Emi, M., Wu L.L, Robertson M.A, Mayres R.L, Hegele R.A, Williams R.R, White R, Laloulel $\mathrm{J}-\mathrm{M}$. Genotyping and sequence analysis of apolipoprotein E isoforms. Genetics, 1988; 3:373379.

16. Corbo RM, Scacchi R, Apolipoprotein E (APOE) allele distribution in the world. Is APOE å4 a ' thrifty' allele? Ann. Hum. Genet. 1999; 63:301-10.

17. Kuwano R, e t al., Dynamin-binding protein gene on chromosome 10q is associated with late-onset Alzheimer's disease, Hum. Mol. Genet. 2006;15:2170-2182.

18. Miyashita A, et al., Genetic association of CTNNA3 with late-onset Alzheimer's disease in females, Hum. Mol. Genet. 2007;16:2854-2869.

19. Mengying L, Chen B, Jiqiang Z, Feng W. Apolipoprotein E gene polymorphism and Alzheimer's disease in Chinese population: a meta-analysis. Scientific reports. 2014;4:4383. DOI: $10.1038 /$ srep04383

20. Liu GY, Yao LF, Liu JF, Jiang YS, Ma GD, Chen ZG, Zhao B, Li KS. Cardiovascular disease contributes to Alzheimer's disease: evidence from large-scale genome-wide association studies. Neurobiol Aging. 2014;35: 786-792.

21. Richard AA. Risk factors for Alzheimer's disease. Folia Neuropathol. 2019;57(2):87- 105.

22. Marottoli FM, Katsumata Y, Koster KP, Thomas R, Fardo DW, Tai LM. Peripheral inflammation, 
apolipoprotein E4, and amyloid-interact to induce cognitive and cerebrovascular dysfunction. $A S N$ Neuro.,2017; 9: 10.1177/1759091417719201.

23. Polvikoski T, Sulkava R, Haltia M, et al. Apolipoprotein E, dementia, and cortical deposition of Beta-amyloid protein. The New England Journal of Medicine.1995; 333(19): 1242-1247.

24. Fryer JD, Taylor JW, DeMattos RB, Bates KR, Paul SM, Parsadamian M, Holtzman DM. Apolipoprotein E markedly facilitates age-dependent cerebral amyloid angiopathy and spontaneous hemorrhage in amyloid precursor protein transgenic mice. $J$ Neurosci. 2003;23:7889-7896.
25. Kamran N, Insha R, Arshad H, Parvaiz AS, Bashir AG. Association of AngiotensinConverting Enzyme gene polymorphism and Alzheimer's risk in Kashmiri population. Gene Reports. 2021;25:101309. doi.org/10.1016/j. genrep.2021.101309

26. Lambert JC, Mann D, Richard F, Tian J, Shi J, Thaker U, Merrot S, Harris J, Frigard B, Iwatsubo T, Lendon C, Amouyel P. Is there a relation between APOE expression and brain amyloid load in Alzheimer's disease? J Neurol Neurosurg Psychiatry.2005;76:928- 933. doi: 10.1136/jnnp.2004.048983. 